05

\title{
Влияние термоциклирования на мартенситные превращения сплавов (TiNiMoFe)Ag
}

\author{
(ㄱ Г.А. Байгонакова, Е.С. Марченко, В.Э. Гюнтер
}

Томский государственный университет

E-mail: gat27@mail.ru

Поступило в Редакцию 23 декабря 2016 г.

Исследовано влияние состава и термоциклирования на фазовые превращения многокомпонентных сплавов ( $\mathrm{TiNiMoFe}) \mathrm{Ag}$ с содержанием серебра до 1.5 at.\%. На основе температурной зависимости удельного электросопротивления исследуемых сплавов определены характеристические температуры и построена диаграмма мартенситных превращений. Выявлена корреляция поведения характеристических температур мартенситных превращений и структурно-фазовых состояний сплавов (TiNiMoFe)Ag.

DOI: 10.21883/PJTF.2017.20.45151.16631

Перспективным направлением в усовершенствовании материала имплантатов из никелида титана является введение в сплав Ag. В работах $[1,2]$, проведенных на тройных сплавах $\mathrm{TiNi}(\mathrm{Ag})$, установлено, что добавка серебра в TiNi с концентрациями 0.6-1.3, 1.7 и 1.9 at.\% влияет на прочность и пластичность материала при сохранении высоких параметров эффекта памяти формы с максимальной обратимой деформацией до $6.4 \%$. Кроме того, в [3] показана возможность появления в сплаве TiNi антибактериальных свойств при добавлении от 1.4 до 3 at.\% Ag. Aнтибактериальный эффект приписан свободным ионам $\mathrm{Ag}^{+}$, выходящим из вторичных фаз чистого серебра, кристаллизованных в матричной фазе TiNi.

При создании конструкций из сплавов на основе никелида титана необходимо учитывать стабильность свойств используемого материала [4]. Известно, что характеристические температуры мартенситных превращений $B 2 \leftrightarrow B 19^{\prime}$ и $B 2 \leftrightarrow R \leftrightarrow B 19^{\prime}$ в TiNi очень чувствительны к термоциклированию [5]. Ранее не проводилось исследований влияния термоциклирования на фазовые превращения (ФП) многокомпонентных 
сплавов (TiNiMoFe)Ag. Настоящая работа посвящена исследованию влияния фазового наклепа на характеристические температуры мартенситных превращений (MП) сплавов (TiNiMoFe) $\mathrm{Ag}$ с содержанием серебра $0,0.1,0.2,0.5,1$ и 1.5 at.\%.

Исследуемые сплавы $\mathrm{Ti}_{50} \mathrm{Ni}_{49.5-x} \mathrm{Mo}_{0.3} \mathrm{Fe}_{0.2} \mathrm{Ag}_{x}(x=0,0.1,0.2,0.5,1$ и 1.5 at.\%.) изготавливались в индукционной печи ИСВ-0.004 ПИ М1 путем переплава губчатого Тi и $\mathrm{Ni}$ марки $\mathrm{H} 1$ с добавлением легирующих элементов $\mathrm{Mo}$, $\mathrm{Fe}$ и $\mathrm{Ag}$. Измерение температурной зависимости удельного электросопротивления $\rho(T)$ осуществлялось потенциометрическим методом. В режиме нагрев-охлаждение-нагрев проводилось циклирование, записывались первый и десятый циклы. Рентгеноструктурные исследования проводились на дифрактометре „XRD-6000“ Shimadzu.

Исследования температурных зависимостей $\rho(T)$ позволяют определить характеристические температуры МП $\left(T_{R}, M_{S}, M_{f}\right)$ в статическом состоянии и по виду зависимости качественно оценить тип МП $\left(B 2 \rightarrow R \rightarrow B 19^{\prime}\right.$ или $\left.B 2 \rightarrow B 19^{\prime}\right)$. На рис. $1, a$ приведены зависимости $\rho(T)$ сплавов (TiNiMoFe)Ag с разным содержанием $\mathrm{Ag}$ (первый цикл). При охлаждении начало перехода из высокотемпературной $B 2$ - в $R$-фазу соответствует росту $\rho(T)$ в точке $T_{R}$. Переход $R \rightarrow B 19^{\prime}$ начинается при температуре $M_{S}$ при резком понижении электросопротивления и завершается в точке $M_{f}$. Во всех случаях легирования $\mathrm{Ag}$ сплавов (TiNiMoFe) продуктами МП являются ромбоэдрическая $R$ - и моноклинная $B 19^{\prime}$-фазы.

Удельное электросопротивление мартенсита $B 19^{\prime}$ более низкое, чем для высокотемпературной B2-фазы. В сплавах на основе TiNi рост величины $\rho(T)$ при ФП аустенит-мартенсит определяет наличие $R$-фазы [6]. Известно [7], что образование структуры $R$-фазы сопровождается высокой плотностью межкристаллитных двойниковых, антифазных границ и упругопластических искажений решетки в области межфазных границ и, главное, возрастанием дисторсионных искажений в самой $R$-фазе. Все эти структурные изменения при образовании кристаллов $R$-фазы приводят к росту $\rho(T)$ при понижении температуры.

Для всех исследуемых сплавов была рассчитана величина $\Delta \rho=$ $=\rho_{M_{S}}-\rho_{T_{R}}$, которая меняется в зависимости от состава сплава (см. таблицу). Максимальное значение величины $\Delta \rho \approx 13 \mu \Omega \cdot \mathrm{cm}$ приходится на сплав с 1 at.\% Ag, что может характеризовать более неупорядоченную структуру твердого раствора, чем в сплавах с другим содержанием Ag. 


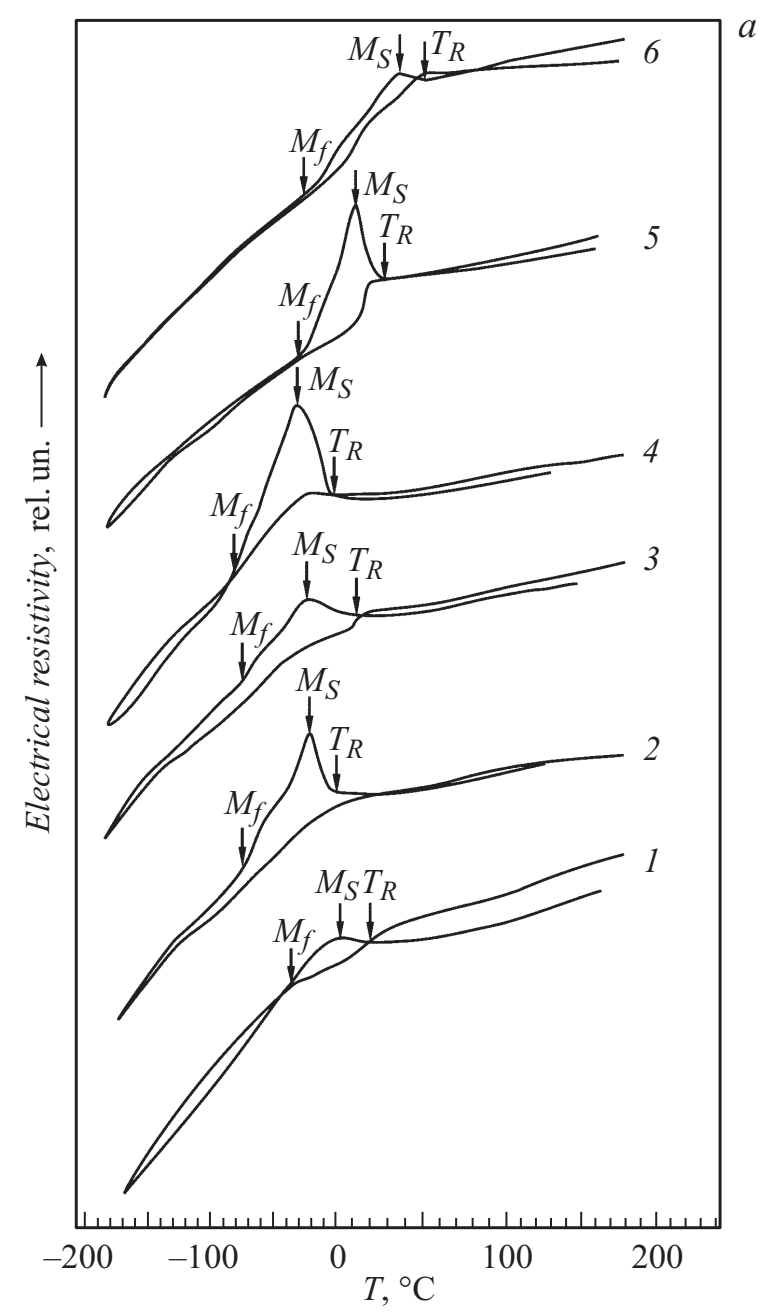

Рис. 1. $a$ - температурные зависимости удельного электросопротивления $\rho(T)$ в сплавах (TiNiMoFe)Ag. $C_{\mathrm{Ag}}$, at.\%: $1-0,2-0.1,3-0.2,4-0.5,5-1$, $6-1.5 . b-$ концентрационная зависимость характеристических температур мартенситных превращений сплавов (TiNiMoFe) $\mathrm{Ag}$.

Письма в ЖТФ, 2017, том 43, вып. 20 


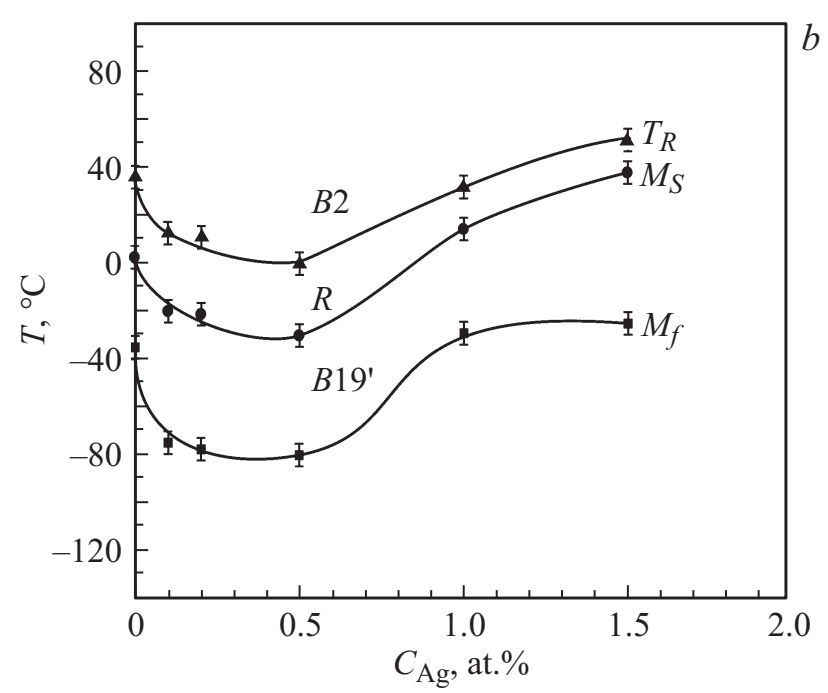

Рис. 1 (продолжение).

На основе анализа зависимостей $\rho(T)$ были определены характеристические температуры МП $\left(T_{R}, M_{S}, M_{f}\right)$ и построена их диаграмма (рис. $1, b)$. Легирование малыми концентрациями $\mathrm{Ag}$ (до 0.5 at.\%) приводит к снижению характеристических температур МП $\left(T_{R}, M_{S}, M_{f}\right)$ на $20-30^{\circ} \mathrm{C}$. Серебро с концентрациями 1 и 1.5 at.\% повышает характеристические температуры на $15-35^{\circ} \mathrm{C}$ и смещает ФП $B 2 \leftrightarrow R \leftrightarrow B 19^{\prime}$ в область более высоких температур (рис. $1, b$ ). Важной особенностью сплавов на основе никелида титана, легированных серебром, является то, что Ag может как понижать, так и повышать характеристические температуры МП. Это имеет практическое значение, так как элемент $\mathrm{Ag}$ позволяет незначительно регулировать и смещать температуры фазовых превращений.

На рис. 2 приведены рентгенограммы исходного сплава $(a)$ и сплава с 1 at.\% $\mathrm{Ag}(b)$. Установлено, что основной фазой в этих сплавах является аустенитная высокотемпературная B2-фаза. Уширение и закономерное расщепление структурных линий исходной $B 2$-фазы [110], [200], [211], [220] и [310] - свидетельствуют о наличии ромбоэдрической $R$-фазы. Также на рентгенограммах данных сплавов выявлены структурные рефлексы моноклинной мартенситной фазы $B 19^{\prime}$ с малой 
Значения величин удельного электросопротивления и характеристических температур МП для всех исследуемых сплавов после первого и десятого циклов

\begin{tabular}{c|c|c|c|c|c|c|c|c}
\hline \multirow{2}{*}{$\begin{array}{c}\text { Ag } \\
\text { at.\% }\end{array}$} & \multicolumn{2}{|c|}{$\Delta \rho, \mu \Omega \cdot \mathrm{cm}$} & \multicolumn{2}{c|}{$M_{S}, \mathrm{~K}$} & \multicolumn{2}{c|}{$M_{f}, \mathrm{~K}$} & \multicolumn{2}{c}{$T_{R}, \mathrm{~K}$} \\
\cline { 2 - 8 } & 1 цикл & $\begin{array}{c}10 \text { цик- } \\
\text { лов }\end{array}$ & 1 цикл & $\begin{array}{c}10 \text { цик- } \\
\text { лов }\end{array}$ & 1 цикл & $\begin{array}{c}10 \text { цик- } \\
\text { лов }\end{array}$ & 1 цикл & $\begin{array}{c}10 \text { цик- } \\
\text { лов }\end{array}$ \\
\hline 0 & 3 & 3.5 & 3 & -2 & -35 & -42 & 21 & 39 \\
0.1 & 5 & 8 & -20 & -29 & -154 & -119 & 1 & 12 \\
0.2 & 2 & 7 & -22 & -24 & -175 & -98 & 13 & 12 \\
0.5 & 10 & 12 & -30 & -38 & -80 & -89 & 0 & 0 \\
1.0 & 13 & 15 & 13 & -11 & -29 & -88 & 29 & 40 \\
1.5 & 5 & 6 & 38 & 32 & -25 & -23 & 52 & 56
\end{tabular}

интенсивностью. Таким образом, в исследуемых сплавах имеет место двустадийное МП: $B 2 \rightarrow R \rightarrow B 19^{\prime}$, что хорошо согласуется с данными $\rho(T)$, где рост удельного электросопротивления характеризует наличие $R$-фазы.

На рентгенограмме сплава без $\mathrm{Ag}$ (рис. 2, $a$ ) обнаружено присутствие структурных линий вторичной фазы $\mathrm{Ti}_{2} \mathrm{Ni}$ (не более $5 \%$ ). Добавка 1 at.\% Ag приводит к снижению объемной доли фаз $B 2$ и $\mathrm{Ti}_{2} \mathrm{Ni}$. Малая объемная доля вторичной фазы $\mathrm{Ti}_{2} \mathrm{Ni}$ отражает факт ее растворения в матричной фазе сплава, что приводит к изменению состава твердого раствора в сторону увеличения титана. Известно, что незначительное увеличение титана в матрице сплава вызывает рост характеристических температур МП [8]. Эти данные коррелируют с результатами $\rho(T)$ и объясняют смещение температуры $M_{S}$ в высокотемпературную область.

Одним из важных параметров, характеризующих свойства сплавов $\mathrm{TiNi}$, является способность сплава изменять форму в условиях постоянно действующей нагрузки как при охлаждении, так и при нагреве, т.е. деформироваться при термоциклировании через интервалы ФП. Влияние термоциклирования на характеристические температуры ФП проявляется во многих факторах. Первый связан с тем, что образование мартенситной фазы сопровождается выделением скрытой теплоты фазового перехода при превращении $B 2 \rightarrow B 19^{\prime}$, вызывающей в условиях повышенной температуры на границе раздела фаз образование выделений вторичных фаз в виде областей частиц типа $\mathrm{Ti}_{2} \mathrm{Ni}, \mathrm{Ni}_{3} \mathrm{Ti}$ и др. Частицы в первую очередь изменяют состав матричного сплава

5 Письма в ЖТФ, 2017, том 43, вып. 20 

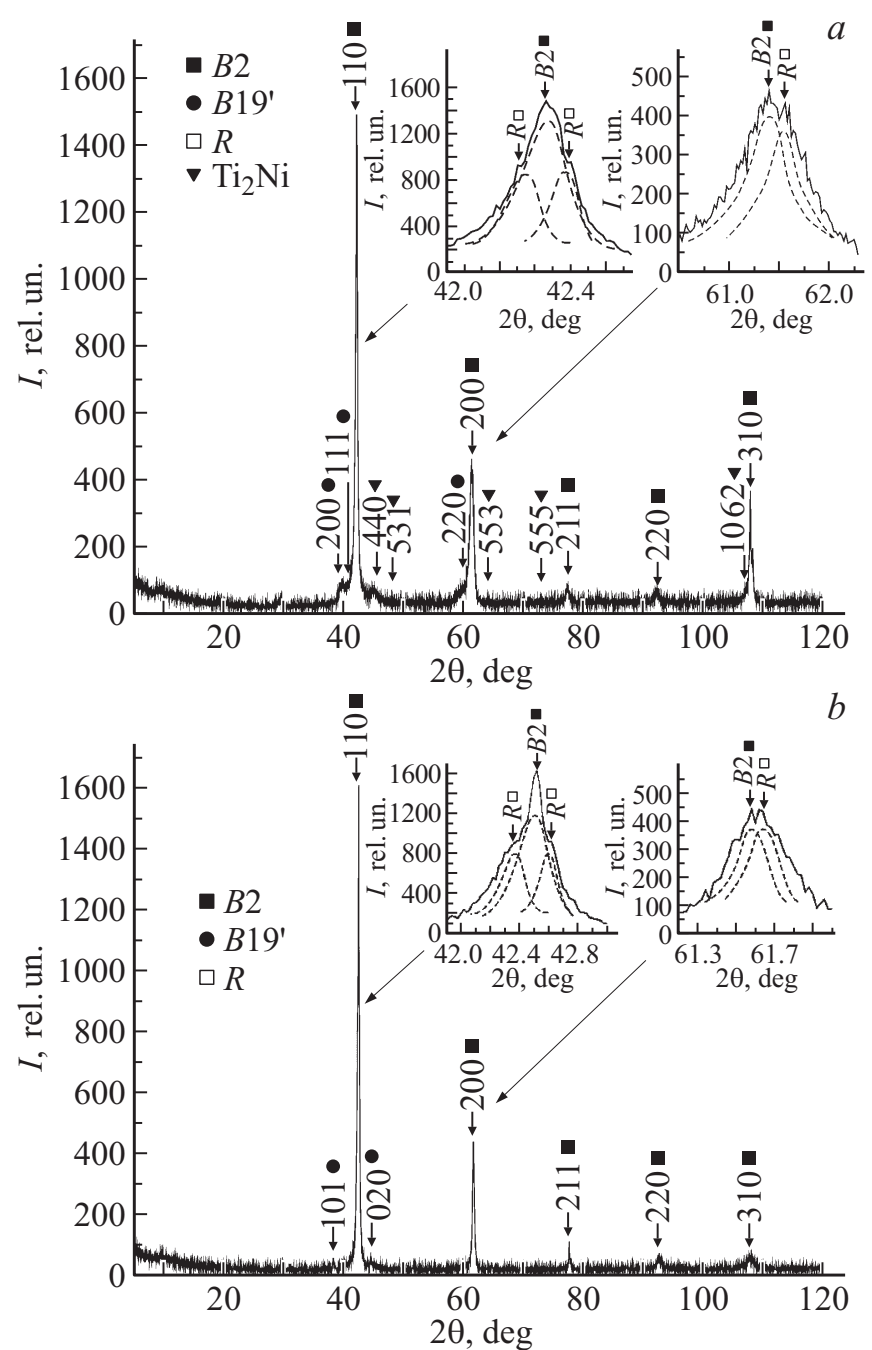

Pис. 2. Рентгенограммы образцов: $a-$ исходный сплав (TiNiMoFe) без добавки $\mathrm{Ag}, b-$ сплав (TiNiMoFe) $\mathrm{Ag}$ с 1 at.\% Ag. Точками показаны B2-фаза, мартенситная фаза $B 19^{\prime}, R$-фаза, $\mathrm{Ti}_{2} \mathrm{Ni}$. 
$\mathrm{TiNi}$, увеличивая или уменьшая концентрацию элементов $\mathrm{Ti}$ и $\mathrm{Ni}$. В соответствии с этим температура $M_{S}$ понижается при избытке никеля в матрице или повышается при избытке титана. Второй фактор связан с образованием и ростом под действием нагрузки мартенситных кристаллов, что сопровождается на межфазной границе релаксацией напряжений и пластическим сдвигом. Пластически деформированные области матрицы не только не участвуют в перестройке структуры при фазовом переходе, но и препятствуют движению межфазной границы. Третий фактор связан с созданием высоконапряженных областей в матрице в процессе образования кристаллов мартенситной фазы, которые в соответствии с уравнением равновесия Клапейрона-Клаузиуса [8] приводят к смещению температуры ФП в область более высоких температур

$$
\Delta \sigma=k \Delta T
$$

где $\Delta \sigma-$ изменение внутренних напряжений, $k-$ коэффициент пропорциональности, $\Delta T$ - изменение температуры равновесия. Увеличение числа термоциклов приводит к стабилизации вкладов. Поэтому если перед применением сплава провести его термоциклирование, то он приобретает более стабильные свойства.

Значения характеристических температур МП для всех сплавов после первого и десятого циклов приведены в таблице. В ходе термоциклирования во всех сплавах последовательность МП $B 2 \rightarrow R \rightarrow B 19^{\prime}$ при охлаждении не меняется. При этом обнаружен рост величины $\Delta \rho$ при понижении температуры вследствие структурного усложнения кристаллов $R$-фазы.

Термоциклирование во всех рассматриваемых случаях легирования приводит к снижению температуры $M_{S}$, стабилизируя исходную B2-фазу. В сплаве с 1 at.\% Ag обнаружено наиболее сильное его влияние на температуру $M_{S}\left(M_{S}\right.$ уменьшается почти на $\left.20^{\circ} \mathrm{C}\right)$. Это может быть связано с наиболее сильным изменением упругопластических свойств сплава в результате легирования Ag. Серебро провоцирует рост дефектов в матричной фазе, и для образования мартенситных кристаллов при термоциклировании необходимо значительно большее переохлаждение.

Таким образом, в сплавах на основе никелида титана при легировании $\mathrm{Ag}$ наблюдается рост величины удельного электросопротивления, который связан с изменением структурно-фазового состава сплава. Характеристические температуры МП чувствительны к изменению

$5^{*}$ Письма в ЖТФ, 2017, том 43, вып. 20 
состава сплавов. Легирование сплавов на основе никелида титана небольшими концентрациями $\mathrm{Ag}(0.1-0.5$ at.\%) приводит к снижению температуры $M_{S}$ на $20-30^{\circ} \mathrm{C}$, а при концентрациях свыше 0.5 at.\% к росту $M_{S}$ и смещению фазовых переходов $B 2 \leftrightarrow R \leftrightarrow B 19^{\prime}$ в область более высоких температур.

Во всех исследуемых сплавах при термоциклировании последовательности МП $B 2 \rightarrow R \rightarrow B 19^{\prime}$ не меняются, но сопровождаются фазовым наклепом с разной степенью проявления. Максимальный уровень фазового наклепа наблюдается в сплаве с 1 at.\% $\mathrm{Ag}$ со снижением $M_{S}$ на $20^{\circ} \mathrm{C}$. Во всех остальных случаях эта величина не превышает $8^{\circ} \mathrm{C}$.

\section{Список литературы}

[1] Chun S.-J., Noh J.-P., Yeom J.-T., Kim J.-I., Nam T.-H. // Intermetallics. 2014. V. 46. P. $91-96$.

[2] Zamponi C., Wuttig M., Quandt E. // Scripta Mater. 2007. V. 56. N 12. P. $1075-1077$.

[3] Zheng Y.F., Zhang B.B., Wang B.L., Wang Y.B., Li L., Yang Q.B., Cui L.S. // Acta Biomater. 2011. V. 7. N 6. P. 2758-2767.

[4] Ходоренко В.Н., Кафтаранова М.И., Гюнтер В.Э. // Письма в ЖТФ. 2015. T. 41. B. 6. C. $81-89$.

[5] Ясенчук Ю.Ф., Артюхова Н.В., Гюнтер В.Э. // Письма в ЖТФ. 2015. Т. 41. B. 18. C. $60-67$.

[6] Gunther V.E,. Marchenko E.S., Baigonakova G.A. // Mater. Today: Proc. 2017. V. 4. N 3. P. 4727-4731.

[7] Клопотов А.А., Гюнтер В.Э., Чекалкин Т.Л., Козлов Э.В. // Письма в ЖТФ. 2002. T. 28. B. 19. C. $17-23$.

[8] Гюнтер В.Э., Ходоренко В.Н. и др. // Медицинские материалы и имплантаты с памятью формы. Томск: НПП МИЦ, 2011. Т. 1. С. 533. 